\title{
BMJ Open To dialyse or delay: a qualitative study of older New Zealanders' perceptions and experiences of decision-making, with stage 5 chronic kidney disease
}

\author{
Sarah Lovell, ${ }^{1}$ Robert J Walker, ${ }^{2}$ John B W Schollum, ${ }^{2}$ Mark R Marshall,,${ }^{3,4,5}$ \\ Bronwen M McNoe, ${ }^{6}$ Sarah Derrett ${ }^{6}$
}

To cite: Lovell S, Walker RJ, Schollum JBW, et al. To dialyse or delay: a qualitative study of older New Zealanders' perceptions and experiences of decisionmaking, with stage 5 chronic kidney disease. BMJ Open 2017;7:e014781.

doi:10.1136/bmjopen-2016014781

- Prepublication history for this paper is available online. To view these files please visit the journal online (http://dx.doi.org/10.1136/ bmjopen-2016-014781).

Received 19 October 2016 Revised 30 January 2017 Accepted 16 February 2017

CrossMark

For numbered affiliations see end of article.

Correspondence to Professor Robert J Walker; rob.walker@otago.ac.nz

\section{ABSTRACT}

Background: Issues related to renal replacement therapy in elderly people with end stage kidney disease (ESKD) are complex. There is inadequate empirical data related to: decision-making by older populations, treatment experiences, implications of dialysis treatment and treatment modality on quality of life, and how these link to expectations of ageing.

Study population: Participants for this study were selected from a larger quantitative study of dialysis and predialysis patients aged 65 years or older recruited from three nephrology services across New Zealand. All participants had reached chronic kidney disease (CKD) stage 5 and had undergone dialysis education but had not started dialysis or recently started dialysis within the past 6 months.

Methodology: Serial qualitative interviews were undertaken to explore the decision-making processes and subsequent treatment experiences of patients with ESKD.

Analytical approach: A framework method guided the iterative process of analysis. Decision-making codes were generated within NVivo software and then compared with the body of the interviews.

Results: Interviews were undertaken with 17 participants. We observed that decision-making was often a fluid process, rather than occurring at a single point in time, and was heavily influenced by perceptions of oneself as becoming old, social circumstances, life events and health status.

Limitations: This study focuses on participants' experiences of decision-making about treatment and does not include perspectives of their nephrologists or other members of the nephrology team.

Conclusions: Older patients often delay dialysis as an act of self-efficacy. They often do not commit to a dialysis decision following predialysis education. Delaying decision-making and initiating dialysis were common. This was not seen by participants as a final decision about therapy. Predialysis care and education should be different for older patients, who will delay decision-making until the time of facing obvious uraemic symptoms, threatening blood tests or paternalistic guidance from their nephrologist.

\section{Strengths and limitations of this study}

- Decision-making with respect to renal replacement therapy was a fluid process influenced by their perception of age, social circumstances, life events and health status.

- Delayed decisions were very common and frequently misunderstood by nephrologists as opting for conservative care.

- Predialysis care and education needs to be different for older patients.

- Limitation: small numbers interviewed. Patient focus only does not include nephrologists' perspective and may have limited applicability to low-middle-income countries or non-Western countries.

Trial registration number: Australasian Clinical Trials Registry ACTRN 12611000024943; results.

\section{INTRODUCTION}

Population ageing and an 'epidemic' of end stage kidney disease (ESKD) among older people are driving demand for dialysis. ${ }^{1}$ The needs of this group are usually more complex than those of younger patients, given their increased prevalence of multimorbidity, subsequent frailty and functional dependence, and relatively short longevity. ${ }^{2}$ This situation limits the applicability of traditional paradigms for managing dialysis in the elderly, necessitating a more individualised approach. ${ }^{3-5}$ Core questions, intersecting age and clinical need, influence decisions of dialysis in the elderly-pertaining to the question of 'if' and also 'when'.

It is axiomatic that delivery of dialysis to the elderly incorporates patient-centred outcomes. Relevant research has highlighted 
concerns among elderly patients that dialysis will impede their freedom, ${ }^{4}$ that they, and their partners, can feel overwhelmed by the impact of dialysis on their lives, and the extent to which they must adjust to the imposition of dialysis. ${ }^{6}{ }^{7}$ In addition, the relatively short longevity of older patients means that the impact of time spent dialysing or travelling to dialysis is different in the elderly compared with those who are younger. ${ }^{2} 89$ In recent years, these factors have increasingly influenced the healthcare delivery of dialysis to the elderly. For instance, conservative management, that is, the active management of symptoms without resorting to dialysis, has been increasingly adopted for elderly patients who are concerned about the burden of dialysis, ${ }^{10-12}$ as have assisted and unassisted home-based (as opposed to clinic-based or hospital-based) dialysis therapies. ${ }^{2} 1314$ Such models of care, however, are often developed out of cumulative clinical experience, and the development of systematic approaches has been limited by the inadequate amount of empirical data for: decision-making by older populations, their treatment experiences, the implications of dialysis treatment and treatment modality on quality of life or expectations of ageing.

This study examined the experiences of older adults (aged $\geq 65$ years) living with chronic kidney disease (CKD) as they chose whether or not to begin dialysis or continue with conservative management. We focus on factors that influence decision-making about dialysis and dialysis modality among older New Zealanders with ESKD, within a health delivery system that imposes no restriction on modality selection through reimbursement or policy ${ }^{2} 1516$ This context allows insight into unfiltered patient's perspectives of the progression of CKD, the decision to begin dialysis, and how patients' perceptions of ageing and health status may influence that decision-making process. Such data are critical for developing an evidence-based and patient-centred model of care, and implementing optimal programmatic measures in an effective manner.

\section{METHODS}

This reporting of this study is based on the Consolidated Criteria for Reporting Qualitative Health Research $(\text { COREQ })^{17}$ and the Standards for Reporting Qualitative Research (SRQR). ${ }^{18}$ This study is registered with the Australasian Clinical Trials Registry ACTRN 12611000024943.

\section{Participant selection}

Participants for this study were selected from a larger quantitative study (dialysis outcomes for people with CKD aged $\geq 65$ years (DOS65)). DOS65 takes a censusbased approach, and includes all older CKD5 patients from three nephrology services across New Zealand, each serving different patient populations and varying in organisational and clinical models of dialysis delivery. ${ }^{19}$ The three units were Middlemore Hospital, Hawkes Bay and Southern Region. The Middlemore unit is a large urban centre providing in-centre, satellite and to a lesser extent home haemodialysis as well as peritoneal dialysis in South Auckland, an area with a high proportion of Māori and Pacific Island patients. Hawkes Bay is a smaller regional unit with a more rural population providing in-centre haemodialysis and peritoneal dialysis. The Southern Region is a medium-sized teaching hospital with an exclusively home-based dialysis programme (haemodialysis and peritoneal dialysis). Participants for this qualitative study were purposely selected from DOS65 if they had undergone dialysis education and had reached CKD stage 5 without yet starting dialysis or recently started dialysis within the past 6 months. Participants were approached by their physician at the time of recruitment into the DOS65 and invited to take part in this additional qualitative study. Study sites were selected to maximise ethnic diversity. Initial convenience sampling of eligible patients was modified due to rapid recruitment of male-intended/current peritoneal dialysers. Subsequent purposive sampling ${ }^{20}$ was used to allow us to capture diversity and balance in experiences and opinions among participants and enhance representation of current/intended patients with haemodialysis and non-dialysers. Participants did not receive any reimbursement for participating in the study. Initially, 27 participants were identified for invitation. Of these, five declined and another five were unable to be contacted or meet for the scheduled interview. As a longitudinal qualitative study, serial interviews (serial qualitative interviews (SQIs)) were undertaken with 17 participants (11 from Middlemore Hospital, 1 from Hawkes Bay and 5 from the Southern Region) spaced over a 2-3-year period, to capture the participants' experiences on the decision-making processes and subsequent treatment experiences of patients with CKD stage 5 as they selected and pursued a treatment pathway. ${ }^{91}$

\section{Data collection}

Qualitative interviews were undertaken to explore the temporal changes in the perceptions and needs of patients undergoing transitions in their health and healthcare, specifically related to decision-making processes and subsequent treatment experiences of patients with ESKD. Participants were not known to the interviewer (SL), although SL provided them with the goals for the project as part of the informed consent process. Participants were interviewed in English (face-to-face), at home (only two were interviewed in a clinic setting), close to the time of treatment decision-making to precede key transitions in health status and treatment. Interviews were semistructured drawing from a predetermined set of questions (informed by a previous pilot study ${ }^{13}$ and the wider literature) but with flexibility to pursue ideas raised by participants. ${ }^{22}$ Interviews ceased when theoretical saturation was reached, that is, when few or no new concepts or topics were raised. Serial interviews were spaced to allow for establishing a dialysis routine, stabilised health or decline to end of life care ${ }^{923}$ 


\section{Analysis}

All interviews were audio-recorded and transcribed verbatim. The transcripts were entered into NVivo software and then compared with the body of the interviews (QSR International Pty : NVivo 10.0 edition).

Two authors (SL and SD) coded the transcripts independently, and reconciled any differences by discussion. Coding and thematic analysis followed the principles of framework analysis. ${ }^{22}$ Coding of decision-making interviews saw the inductive generation of initial codes from the data. To address the large amount of data generated through SQI's, a purely deductive review of satisfaction with treatment path options demonstrated a wide range of care trajectories and outcomes during follow-up interviews. The participants' general satisfaction with their own decisions meant follow-up interviews provided few additional insights into their dialysis decision-making in the subsequent interviews. NVivo was used to generate a report of all codes with the corresponding text allowing similar concepts to be grouped into themes. Conceptual links and patterns among themes and subthemes were identified and mapped into a thematic schema. Researcher triangulation was conducted whereby SL and SD discussed the preliminary themes with other researchers (MRM, JBWS, RJW) who read the transcripts independently and confirmed that the themes captured the full range of participants' perspectives. The longitudinal data documented diverse care trajectories among participants but yielded few insights into participant's earlier decision-making behaviour. Pseudonyms have been used in place of participants' actual names.

\section{RESULTS}

Interviews were undertaken with 17 participants. Participant characteristics are presented in table 1 . The first set of interviews (17 participants) took place between March 2011 and April 2012; the second follow-up set (16 out of 17 participants) occurred 6-13 months later and the third and final interviews (11of the 16 participants) took place 22-27 months after the first interview. At the time of the first interview, 4 participants had just started dialysis ( $<3$ months) and by the second interview, two additional participants had started dialysis. One participant was deceased by the second interview and three further individuals died between the second and third interviews. One individual declined to participate in a third interview. In three cases, the final interviews were cancelled (two participants) or substantially delayed (one participant) due to hospitalisations. The current manuscript is primarily informed by the first set of interviews, which generated the greatest amount of data on participants' dialysis decision-making (table 1). In several instances, participant's thoughts on dialysis continued to evolve and data from the second interview was incorporated into the decision-making analysis.

\section{Declining dialysis: independence and dependents}

Maintaining one's independence was a primary concern in dialysis decision-making; those without the practical and emotional support of a spouse gave more serious consideration to declining dialysis. Participants spoke of support from a range of sources, including their

Table 1 Demographics of participants

\begin{tabular}{|c|c|c|c|c|c|c|}
\hline Pseudonym & Sex & Age & Cause of ESRD & $\begin{array}{l}\text { Interview } \\
\text { analysed* }^{*}\end{array}$ & $\begin{array}{l}\text { Comorbidities } \\
(\mathrm{N}) \dagger\end{array}$ & eGFR‡ \\
\hline Jean & Female & 66 & Mesangial proliferative $(\lg A+)$ & 1 & 3 & 12 \\
\hline Dawn & Female & 80 & Uncertain diagnosis & 1 & 5 & 12 \\
\hline Mary & Female & 84 & Renal vascular disease-type unspecified & 1 and 2 & 4 & 14 \\
\hline Raymond & Male & 69 & Obstructive nephropathy & 1 & 4 & 4 \\
\hline Donald & Male & 69 & Polycystic kidney disease & 1 & 2 & 11 \\
\hline Paul & Male & 69 & Presumed glomerular nephritis & 1 & 2 & 13 \\
\hline Graham & Male & 69 & Diabetes-type 2 & 1 & 3 & 12 \\
\hline Marcus & Male & 71 & Uncertain diagnosis & 1 & 2 & 7 \\
\hline Richard & Male & 71 & Renal vascular disease-due to hypertension & 1 & 3 & 8 \\
\hline John & Male & 70 & Renal vascular disease-due to hypertension & 1 & 2 & 12 \\
\hline Vincent & Male & 72 & Diabetes-type 2 & 1 & 5 & 12 \\
\hline Fraser & Male & 75 & Renal cell carcinoma-nephrectomy & 1 & 1 & 7 \\
\hline Malcolm & Male & 75 & Uncertain diagnosis & 1 & 3 & 10 \\
\hline Daniel & Male & 79 & Presumed glomerular nephritis & 1 & 3 & 12 \\
\hline Douglas & Male & 83 & Renal vascular disease-due to hypertension & 1 & 1 & 12 \\
\hline Kevin & Male & 84 & Renal vascular disease-due to hypertension & 1 & 4 & 5 \\
\hline Neville & Male & 90 & Obstructive uropathy & 1 & 1 & 13 \\
\hline
\end{tabular}

*Up to three interviews were carried out with all participants, however only interviews where dialysis decision-making was the focus of the interview, were analysed for the purposes of this paper. Among most participants, there was considerable overlap in content in the follow-up interview(s) with additional new data that informed decision-making only evident in one participant as noted in table.

†Comorbidities were recorded as cardiovascular disease, cerebrovascular disease, peripheral vascular disease, diabetes, lung disease, cancer, musculoskeletal disease and other comorbidities.

feGFR $\left(\mathrm{mL} / \mathrm{min} / 1.73 \mathrm{~m}^{2}\right)$ determined at the time of recruitment into the study.

eGFR, estimated glomerular filtration rate; ESRD, end-stage renal disease. 
children; however, the presence of a supportive spouse was a critical factor in the decision to start dialysis.

Only four participants in our study reported giving serious thought to conservative management; all were aged over 80 and two lived alone while the other two were primary caregivers for their wives who lived with the effects of stroke or dementia. These participants anticipated regular trips to the nephrology unit and dialysis as a tie that would undermine their quality of life and caregiving responsibilities. However, the decision to refuse dialysis was rarely straightforward; only one woman (Dawn, 80) had settled on a decision of conservative management (no dialysis) at the time of our first interview; a further woman (Mary 84) made the same decision ahead of her second interview. Dawn and Mary, were single, living alone and experiencing comorbidities; both saw dialysis as a threat to the weekly social activities they enjoyed. With a strong sense of independence but restricted mobility and only her niece and nephew for support, Dawn did not consider home-based dialysis a viable option. Having cared for her mother for many years, Dawn did not wish to be a 'burden' on anyone. Dawn's fluctuating energy levels also led her to worry about the burden of travelling to the clinic and dialysing in centre:

So [the doctor] said about going on to dialysis and I said that I didn't want to go on there because, I said, it will interfere with my life. I said three days a week, I said, a couple of those days are the days that I might go out .... And I said and I'm getting older and you don't live forever and I don't want to be a burden to anybody cause, you see, [I] got no-you know-well, I've only got nieces and nephews. (Dawn, 80)

All participants discussed the negative impacts that they anticipated dialysis would have on their lifestyle yet, for most, this burden was outweighed by the benefits of a longer life that would see them enjoy more time with their spouse and grandchildren. Experiencing a transition in personal circumstances was identified by participants as a trigger for consideration of conservative management. For example, Neville, 90 years, had been diagnosed with CKD 20 years earlier. He intended to begin dialysis 'when the time came' as it would enable him to continue caring for his wife who was living with the effects of stroke. However, he explained that his wife's presence was critical to the choice to undertake dialysis:

If [she] predeceases me then I've only got to think of myself. A lot would depend on my general health. If she doesn't predecease me well the question [of whether to choose dialysis] doesn't get raised [he would do it when it became necessary to allow him to continue in his role as carer]. (Neville, 90)

Similarly, caregiver Kevin, 84 years, whose wife's advancing dementia was requiring increased care, had no immediate support from family members living nearby. Kevin had already chosen conservative management when a visit from his daughter led him to reconsider that decision:

Last November I felt real crook and ah, I ah, [the doctor] got me in there and they said 'Oh geez, you're right down to eight percent, kidney function' so then they ah, I had to make up my mind. I turned things down for a start. I said 'I'm not going on a machine'. Then this peritoneal dialysis, my daughter [was visiting] so she arranged to meet the specialist, second in charge, and they arranged a meeting in the dialysis unit so that I could see what was going on. It's quite involved ... they had an old chap there, he was 76 , and he was being trained and he said 'Look, I haven't felt better'; he said 'I'm doing things I've never done before'. So my daughter looked at me and I looked at her, I said 'righto, I'll give it a go'. So that's when I had the tube [peritoneal catheter] put in. (Kevin)

For Kevin, problems with the peritoneal catheter meant that he was unable to dialyse and he later reflected that-given the information his doctors had presented him with-choosing dialysis at his age had been a mistake. Kevin, like Mary, found that his inclination to decline dialysis was at odds with the preference of his child and led him to feel pressured to choose dialysis. Kevin was the only participant to regret his dialysis decision, even when taking follow-up interviews into account. All participants considering conservative management shared advancing ages-constituting four of the six $\geq 80$-year olds in the study, yet age appeared intertwined with experiences of health status and social support required (by participants) —and provided by them (to spouses).

\section{The dialysis imperative}

While the decision not to dialyse was dominated by concerns over quality of life, the decision to start dialysis was dominated by concern over length of life. For 13 participants, declining dialysis was not seriously considered an option. Some expressed surprise and disbelief that anyone would choose not to go on dialysis and occasionally this disbelief was accompanied with the disparaging suggestion that choosing not to dialyse was quitting or 'giving up' on life. Many felt they had no choice but to dialyse, an understanding that sometimes appeared linked to their clinician's framing of the decision:

So that's [deciding against dialysis] just a way for dying ... once your kidney goes that's it! (Paul, 69)

When they say I've got to go on [dialysis] then I'll work it in, because I've got no choice. It's either that or die [laughs]. (Malcolm, 75)

If you don't go on dialysis you die. But I don't, like, I don't really want to go on dialysis .... (Vincent, 72)

Despite this acceptance of dialysis as a life-extending mechanism, only two of these 13 participants accepted 
dialysis without delay. These individuals were strongly influenced by their declining health and accepted the recommendations of their treating physician to start dialysis. The remaining 11 chose to delay beginning dialysis, some for years, but had not excluded dialysis as an option.

\section{Delaying dialysis}

Eleven participants qualified their choice to dialyse with statements such as 'when the time comes'. Experiencing fewer effects of ESKD, these participants feared the impact of dialysis on their lifestyle and the implications of reversing a decision to start dialysis. The dominant report-the decision to delay-was often grounded in a concern that dialysis would impinge on everyday activities and ideas of recreational travel that were entwined with many participants' expectations of retirement. Participants anticipated that once on dialysis, their social lives would centre more firmly on the home, day trips would be cut short, work and volunteering would be interrupted, and trips overseas would become difficult or impossible. Most participants felt that home-based dialysis would allow them the greatest flexibility to live their lives as they wanted. Yet there was a tacit acknowledgement that life would irrevocably change:

Well, I'm hoping it's not going to make much difference except for the, the amount of time you waste, you know .... Get up early and have one, have one before twelve or something, you can, or have one late at night, something like, you have to arrange it yourself. So, it'll be a pain in the butt getting used to it, but I know quite a few guys, a mate of mine, he's dead now, he used to, he said you just got used to it. (Paul, 69)

It's more so the inconvenience of it because I'm very active within the community and although I'm retirednevertheless it's-I suppose in a sense it's an intrusion into the normal daily life. Especially if you're going to be travelling around the place, around New Zealand or overseas, although we don't do that all that much now, we used to do a far bit. (Graham, 69)

Well, it's not, not going to change much. We just have to go out every fifth or third day over to [the clinic] for five hours, um, until such time as I'm used to doing it myself. Then the dialysis machine comes here [to own home]. We'll have to get the place plumbed out and sorted out where we're going to put it. (Vincent, 72)

In their efforts to maintain the status quo, it was common for participants to take an active role in monitoring their own kidney function and adopt health-enhancing practices such as appropriate diet and exercise to delay the need for dialysis. Many participants believed their kidney function had yet to decline to a level where their clinician felt dialysis was absolutely necessary. Indeed, two participants had been living with CKD stage 5 for over a decade and considered their health to be stable. These individuals had accumulated considerable expertise and self-efficacy in managing their condition and their decision to delay dialysis was perceived as being supported by their healthcare team. In other instances, the purported decision to 'delay' dialysis was framed as active resistance to their clinician's recommendation they begin dialysis, for example:

I'm not going on dialysis because I think I can manage the situation, I don't know, but it's, that's the plan. In other words, delay it as long as we can so that we just go on and on and on. When that moment arrives you deal with it. It's not going to cause me any great grief I don't think .... I still shower myself, still dress myself all those sorts of things. I have help with drying my lower limbs but, and back, but that's it. I would expect that to continue, so that life just goes on and that we can continue to share in the life of this family and the rest of our family, and share in my grandchildren's lives and all those sorts of things. That's, that's the plan. And, at seventy, there's still a few more years to go on that one. (Marcus, 71)

Marcus was uncomfortable with the speed with which he was encouraged to begin dialysis; he resisted his doctor's recommendation and instead turned to managing his condition through lifestyle, medical and alternative treatments. His decision appeared to be about preserving his present quality of life and routine while retaining the option of dialysis if his own management of his condition was not maintaining this. This subset of participants used a variety of strategies to manage their health, including tracking their blood test results and modifying their lifestyle. Yet underpinning their attitude was a belief that they would begin dialysis when their declining health left them with no other option.

Among the 11 participants who chose to delay dialysis, an assemblage of factors was critical to assessments of the need to begin dialysis: ${ }^{1}$ recommendations of clinicians, ${ }^{2}$ experience of symptoms and ${ }^{3}$ clinical indicators of kidney function. These factors took on varying levels of importance between participants and are discussed below:

\section{Waiting for a clinical directive}

Underpinning many participants' narratives was an anticipation that a time would come when their clinician would signal they could no longer delay dialysis. Many awaited the call from their doctor that it was time to start, for example, one participant's narrative placed the clinician as central to the decision to initiate dialysis:

At the moment he's sitting on the, on his, hands and saying 'Well, it doesn't look like it'll be happening until sometime next year'. (Douglas, 83)

Such reliance on the clinicians contrasted heavily with the actions of many other participant's self-management of their health and expectations of patient-centred care. In one instance, a decision to begin dialysis was made by 
a patient's nurse and the participant and his wife remained satisfied that this was the right call:

I lost hearing, I'd lost memory, I'd lost sight. I don't know about hearing-I think I could hear alright-but ... my memory wasn't good. I was just going downhill quite quickly .... I wouldn't be here if it wasn't for the dialysis .... I had no option at the finish. The girl [nurse], what's her name? Who was it? [Susan] came in and said 'You'll be on dialysis 8 o'clock on Monday'. And I said 'Will I?' and she said 'Yes' [laughs]! So that was it. I didn't make that decision .... I'll take everything to the end-but once I'm at the end of the piece of string I'll recognise it. (Barry, 76)

Barry had chosen to delay dialysis for as long as possible and during his interview, he told several stories that highlighted the impact his kidney condition was having on his cognitive functioning. While he and his wife had identified dialysis as their preferred treatment path, it was only retrospectively that he was aware of how his decision to delay dialysis for so long was impacting his health.

\section{Symptoms and physical decline}

Participants often either failed to attribute their symptoms to CKD or assigned the cause of their symptoms to another condition or the general ageing process, as evident in the case of a participant who reported his memory had declined prior to beginning dialysis:

... and what do they call it, it's a test they do, help, [long pause] give your blood and you, and I forgot to mention, I must have dementia or something. Something-oh, it'll come to me. (Paul, 69)

It knocks your, as far as your appetite's concerned-and perhaps I didn't realise with the information that I gotthat, that it would do it. I still, I still don't eat as much as I used to, that's for sure. And ... I could usually eat everything, just like to, like to enjoy my meals. (Richard, 70)

The most common effect of ESKD that participants identified was exhaustion. This was measured in a wide range of ways, from one's ability to get around 18 holes on the golf course to completing domestic chores. Among those who accepted that their tiredness was due to their CKD, most struggled with the loss of motivation and inability to do things they previously took for granted. The absence-or lack of awareness-of symptoms has implications for the timing of dialysis as participants struggled to reconcile their perceptions of health with information that they needed to begin dialysis:

Thinking back I felt as though 'Why, if I feel as I do at the moment and why, as active as I am at the moment, would I think about going on to dialysis?' It seems ridiculous. (John, 70)

For a small number, the decision to begin dialysis was preceded by a marked decline in physical function that led to their acceptance that dialysis was necessary, as Jean explained:

So you, you do your best for a while, and I feel okay, so it's alright. See, kidney failure is a thing that just creeps up gradually so you just, you cope with it day by day, not realising that you're getting worse and worse all the time. So I know other people of my age that, I'm not functioning like they are. They're having a good time. I can't mow my lawns and all that sort of stuff, so that's why I'm here [training for dialysis]. (Jean, 66)

For these participants, dialysis was viewed as a means of freeing them from their increasingly constrained activities. These individuals hoped dialysis would enable them to become more physically active and carry out the activities that had once been central to their lives, as one participant explained:

What do I want to achieve? Just a normal lifestyle, yeah, and I'm getting it. Yeah, once I get my hips right I'm getting it. I'll be right, good as gold again .... Out there, working on the farm, yeah. My son's taken over the farm but I give him a hand. I haven't been able to do anything for the last nearly twelve months now. (Richard, 71)

Implicit in this narrative is the expectation that the benefits of dialysis would outweigh the effort of maintaining dialysis treatment. Such views highlight the diversity of patient perceptions by running counter to the dominant narrative of dialysis as a burden.

\section{DISCUSSION}

Our study identified three main themes. The most novel finding of our study is that older patients deliberately delay dialysis initiation as an act of self-efficacy and to manage their own health. Although we did not assess their self-efficacy directly, our data suggest that delaying dialysis arises from the increased confidence and capability of patients to manage their own health, ${ }^{24}$ rather than the opposite. This was a common finding among participants who had opted for eventual dialysis as well as for those who had not made a clear decision to dialyse or to opt for an interim strategy of conservative treatment. This is in contrast to the perceptions of nephrologists, who often perceive the delaying of dialysis as resistance to dialysis and denial of the seriousness of their condition. This was illustrated in relation to one participant who was described by his clinician as a "nondialyser' whereas in the qualitative interview, the same man was adamant that he was simply 'delaying dialysis'. The other two main themes confirmed previous studies that patients prioritise factors that preserve their independence, and that the decision to dialyse is dominated by concern over length of life, as opposed to the decision not to dialyse which is driven by quality of life. ${ }^{25}$

The implication for health service delivery is that predialysis education in the older age group is a multistaged process where the ultimate decision for dialysis versus 
conservative care is made by the patient around the time of onset of uraemia. In younger patients, this is regarded as 'crash starting', but among elderly, this should be seen as appropriate: a decision made a year in advance is likely to be made in a clinical context that is no longer appropriate at the time of decision-making. This paper suggests the physicians should work with patients to ensure that they are fully equipped to make a robust and shared decision in the future, but not pressure them to make a definitive decision due to potential changes in the older person's status.

Older patients who decline dialysis are recognised elsewhere as experiencing greater comorbidities; ${ }^{10} 26$ therefore, we would expect the decision to dialyse to be affected by one's stage in the life course. Over the course of interviewing patients over time, we observed that decisionmaking was often a fluid process, rather than occurring at a single point in time, and was heavily influenced by perceptions of oneself as becoming old, social circumstances, life events and health status. We found three indicators that were critical to these perceptions. First, those who did not recognise ESKD symptoms in their day-to-day lives experienced less readiness to begin dialysis than those who experienced declining health. Second, participants anticipated a clear directive would come from their clinician that it was time to begin dialysis and commonly perceived this omission as support for further delay of dialysis. Third, participants who actively managed their condition without dialysis-commonly those for whom the progression of their CKD has been slow, with few symptoms attributable to their CKD-likewise saw stable blood test results as indicators of appropriate delay.

These findings suggest that timing of dialysis initiation may be modified by clearer communication between patients (and their carers or supporters) and the clinical team (nephrologists and predialysis educators). These should clearly identify and focus on symptoms and effects of CKD to cultivate patient readiness for the initiation of dialysis and support self-management of their disease. Given their non-specific nature, the clinical team should revisit the symptoms and effects of CKD regularly, and make specific enquires about them during patient follow-up. Predialysis education for this older age group needs to be more explicit with respect to the natural progression of CKD and the long latency between starting predialysis education and the subsequent need to make a shared decision about the type of ESKD management. Patients who described actively selfmanaging their condition relied heavily on the benchmarks for initiating dialysis communicated by their clinicians. Blood test results and symptoms were effective gauges of the effects of any lifestyle and dietary changes.

The cohort of participants in our study felt relatively well at enrolment, in contrast to previous studies that reported denial of the severity of ESKD in the face of frankly uraemic symptoms. ${ }^{27}$ This situation reflects the clinical reality of CKD care and dialysis decision-making in most predialysis patients, be they younger or older- the majority of patients begin discussions about dialysis at an earlier stage and in a relatively better state of health, compared with when they start dialysis. Our study is the first of its kind to assess older patients' longitudinal experiences of the entire CKD spectrum, and has allowed us to identify the key patient paradigm of delaying dialysis as a strategy to preserve quality of life; anticipating dialysis would impinge on their everyday activities. Clarity around 'delay' versus 'denial' of dialysis might be improved by better patient understanding of progression of CKD to ESKD, especially in relation to onset of symptoms.

In our study, conservative management was seriously considered only by four older participants, for whom in-centre dialysis was their proposed treatment pathway rather than home dialysis, which was precluded by a perceived lack of support to manage home dialysis. The perceived burden of clinic-based treatment was sufficient threat to the quality of life of two of these participants that they declined dialysis. Elsewhere, studies examining patient decision-making processes for dialysis found that where in-centre dialysis was the only option available, this had a significant impact on older patients' perceptions of independence and normal activities of living. ${ }^{9} 25$ In contrast, previous New Zealand research has shown home-based dialysis to be highly acceptable to older adults, even when patients resided more than 1 hour from specialist services. ${ }^{13}$ Whereas little difference in quality of life is evident between older patients on haemodialysis and peritoneal dialysis, ${ }^{28}$ the availability of home dialysis appears to be a positive impact on quality of life, even for older patients. ${ }^{14}$

This study seeks only to represent the perceptions, experiences and understandings of older patients living with ESKD. By focussing on participants' experiences of decision-making, we have not included the perspectives of clinicians and/or the broad range of factors that influence their interactions with the participants discussed here. This may or may not been seen as an imitation, but addresses an important gap in the literature in contrast the comparatively well-reported attitudes of and experiences of clinicians. ${ }^{25}{ }^{27}$ Importantly, the external validity of our study is limited to similarly developed Western nations as New Zealand. Our findings are less generalisable to countries with constrained healthcare resources (eg, developing nations, where access to care rather than patient choice determines healthcare delivery), or with significantly different cultural orientations (eg, familism in context of Confucian cultures such as Taiwan, where filial piety often precludes conservative care for end-stage renal disease (ESRD) $)^{29-31}$.

A strength of our study is its internal validity, insofar as assessments have been undertaken in the context of New Zealand's publicly funded healthcare system-the shared decision to dialyse, or not, is made independently of clinician reimbursement or the ability of patients to pay for dialysis. ${ }^{12} 13$ The assessment of methodological rigour for qualitative research (as opposed to 
reporting rigour) is often discussed in the literature but is yet to be standardised. ${ }^{18}{ }^{32}$ Notwithstanding, by using a tool of quality appraisal for qualitative research tool such as the Critical Appraisal Skills Programme (CASP) Qualitative Research Checklist, ${ }^{33}$ our study has a high degree of methodological rigour over the 10 domains of assessment.

In summary, this qualitative study has identified key points that underlie the older patient's perspective related to decision-making to manage their ESKD. This adds to an increasing understanding of the importance of clear discussions between the individual, their family and the clinical team involved in their care. ${ }^{3-5}$ Such an individualised approach should prioritise the modifiable outcomes patients value most, and acknowledge that observed signs and symptoms often reflect the complex interplay between CKD, ageing and associated comorbidities. Prognostic information related to these and other outcomes are generally used to shape rather than dictate treatment decisions. ${ }^{34}$ An individualised patient-centred approach to care may have more to offer than a traditional disease-based approach to ESKD for many older adults. ${ }^{35}$ This study along with the prospective longitudinal quality of life data is being generated from our larger study ${ }^{19}$ will inform the development of decision aids and clinical guidelines that include the older patients' preferences, autonomy and need to remain an active member of their community.

\section{Author affiliations \\ ${ }^{1}$ School of Health Sciences, University of Canterbury, Christchurch, New Zealand \\ ${ }^{2}$ Department of Medicine, University of Otago, Dunedin, New Zealand ${ }^{3}$ Department of Renal Medicine, Counties Manukau Health, Auckland, New Zealand \\ ${ }^{4}$ School of Medicine, University of Auckland, Auckland, New Zealand \\ ${ }^{5}$ Medical Affairs, Baxter Healthcare (Asia) Pte Ltd, Singapore \\ ${ }^{6}$ Department of Preventive and Social Medicine, University of Otago, Dunedin, New Zealand}

Contributors This was an investigator-initiated and analysed study. RJW, SD and MRM were responsible for the concept of the study. SL undertook the interviews. SL and SD undertook the analyses of the interviews. BMM was responsible for all demographic data collection. Researcher triangulation was conducted whereby SL and SD discussed the preliminary themes with other researchers (MRM, JBWS, RJW), who read the transcripts independently and confirmed that the themes captured the full range of participants' perspectives. All authors (SL, SD, BMM, MRM, JBWS, RJW) contributed to the interpretation of the results and the preparation of the manuscript. RJW is the principal investigator for D0S65, and SD JBWS, MRM and BMM are D0S65 coinvestigators.

Funding The study was supported by Health Research Council of New Zealand (grant number 10/354).

Disclaimer The affiliation with Baxter Healthcare (Asia) of Mark Marshall does not alter the authors' adherence to PLOS ONE policies on sharing data and materials.

Competing interests MRM is full-time employee of Baxter Healthcare (Asia) Pte, Singapore. Baxter Healthcare has had no input whatsoever into this study. The other authors have no potential or actual conflicts of interest related to this study.

Ethics approval This study was approved by the New Zealand Multiregional Ethics Committee, approval number MEC/10/084.
Provenance and peer review Not commissioned; externally peer reviewed.

Data sharing statement No additional data are available.

Open Access This is an Open Access article distributed in accordance with the Creative Commons Attribution Non Commercial (CC BY-NC 4.0) license, which permits others to distribute, remix, adapt, build upon this work noncommercially, and license their derivative works on different terms, provided the original work is properly cited and the use is non-commercial. See: http:// creativecommons.org/licenses/by-nc/4.0/

\section{REFERENCES}

1. Tattersall J. Dialysis in the over-80s. Age Ageing 2005;34:100-1.

2. Brown EA, Johansson L. Dialysis options for end-stage renal disease in older people. Nephron Clin Pract 2011;119(Suppl 1):c10-13.

3. Treit K, Lam D, O'Hare AM. Timing of dialysis initiation in the geriatric population: toward a patient-centered approach. Semin Dial 2013;26:682-9.

4. Harwood L, Clark AM. Dialysis modality decision-making for older adults with chronic kidney disease. J Clin Nurs 2014;23:3378-90.

5. Chandna SM, Da Silva-Gane M, Marshall C, et al. Survival of elderly patients with stage 5 CKD: comparison of conservative management and renal replacement therapy. Nephrol Dial Transpl 2011;26:1608-14.

6. Elliott BA, Gessert CE, Larson PM, et al. Shifting responses in quality of life: people living with dialysis. Qual Life Res 2014;23:1497-504.

7. Madhan K. The epidemic of elderly patients with dialysis-requiring end-stage renal disease in New Zealand. N Z Med J 2004;117: U912.

8. Brown MA, Collett GK, Josland EA, et al. CKD in elderly patients managed without dialysis: survival, symptoms, and quality of life. Clin J Am Soc Nephrol 2015;10:260-8.

9. Morton RL, Snelling P, Webster AC, et al. Factors influencing patient choice of dialysis versus conservative care to treat end-stage kidney disease. CMAJ 2012;184:E277-83.

10. Stringer S, Baharani J. Why did I start dialysis? A qualitative study on views and expectations from an elderly cohort of patients with end-stage renal failure starting haemodialysis in the United Kingdom. Int Urol Nephrol 2012;44:295-300.

11. Llewellyn H, Low J, Smith G, et al. Narratives of continuity among older people with late stage chronic kidney disease who decline dialysis. Soc Sci Med 2014;114:49-56.

12. Thorsteinsdottir B, Swetz KM, Albright RC. The ethics of chronic dialysis for the older patient: time to reevaluate the Norms. Clin J Am Soc Nephrol 2015;10:2094-9.

13. Derrett S, Darmody M, Williams S, et al. Older peoples' satisfaction with home-based dialysis. Nephrology (Carlton) 2010;15:464-70.

14. Rygh E, Arild E, Johnsen E. Choosing to live with home dialysis-patients' experiences and potential for telemedicine support: a qualitative study. BMC Nephrol 2012;13:13.

15. Marshall MR, Walker RC, Polkinghorne KR, et al. Survival on home dialysis in New Zealand. PLoS ONE 2014;9:e96847.

16. Ashton T, Marshall MR. The organization and financing of dialysis and kidney transplantation services in New Zealand. Int $J$ Health Care Finance Econ 2007;7:233-52.

17. Tong A, Sainsbury $P$, Craig J. Consolidated criteria for reporting qualitative research (COREQ): a 32-item checklist for interviews and focus groups. Int J Qual Health Care 2007;19:349-57.

18. O'Brien BC, Harris IB, Beckman TJ, et al. Standards for reporting qualitative research: a synthesis of recommendations. Acad Med 2014;89:1245-51.

19. Walker R, Derrett S, Campbell J, et al. Dialysis outcomes in those aged $\geq 65$ years. BMC Nephrol 2013;14:175

20. Vest JR, Issel LM. Factors related to public health data sharing between local and state health departments. Health Serv Res 2014;49:373-91.

21. Murray SA, Kendall M, Carduff E, et al. Use of serial qualitative interviews to understand patients' evolving experiences and needs. BMJ 2009;334:521-1.

22. Ritchie J, Lewis J, Nicholls C, et al. Qualitative research practice: a guide for social science students and researchers. 2nd Ed. Sage Publications (UK) 2013.

23. Calvin AO. Haemodialysis patients and end-of-life decisions: a theory of personal preservation. J Adv Nurs 2004;46:558-66.

24. Clark NM, Dodge JA. Exploring self-efficacy as a predictor of disease management. Health Educ Behav 1999;26:72-89.

25. Tonkin-Crine S, Okamoto I, Leydon GM, et al. Understanding by older patients of dialysis and conservative management for chronic kidney failure. Am J Kidney Dis 2015;65:443-50. 
26. Carson RC, Juszczak M, Davenport A, et al. Is maximum conservative management an equivalent treatment option to dialysis for elderly patients with significant comorbid disease? Clin J Am Soc Nephrol 2009;4:1611-19.

27. Greer RC, Ameling JM, Cavanaugh KL, et al. Specialist and primary care physicians' views on barriers to adequate preparation of patients for renal replacement therapy: a qualitative study. BMC Nephrol 2015;16:37.

28. Brown $\mathrm{EA}$, Johansson $\mathrm{L}$, Farrington $\mathrm{K}$, et al. Broadening Options for Long-term Dialysis in the Elderly (BOLDE):

differences in quality of life on peritoneal dialysis compared to haemodialysis for older patients. Nephrol Dial Transpl 2010;25:3755-63.

29. Glass AP, Chen LK, Hwang E, et al. A cross-cultural comparison of hospice development in Japan, South Korea, and Taiwan. J Cross Cult Gerontol 2010;25:1-19.
30. Tzeng HM, Yin CY. Family involvement in inpatient care in Taiwan. Clin Nurs Res 2008;17:297-311.

31. Chiu YC. What drives patients to sue doctors? The role of cultural factors in the pursuit of malpractice claims in Taiwan. Soc Sci Med 2010;71:702-7.

32. Côté L, Turgeon J. Appraising qualitative research articles in medicine and medical education. Med Teach 2005;27:71-5.

33. Critical Appraisal Skills Programme (CASP) Qualitative Checklist. 2013. http://www.casp-uk.net/\#!checklists/cb36 (accessed 1 Jan 2015)

34. Ladin K, Weiner DE. Better informing older patients with kidney failure in an era of patient-centered care. Am J Kidney Dis 2015:65:372-4.

35. Bowling CB, O'Hare AM. Managing older adults with CKD: individualized versus disease-based approaches. Am J Kidney Dis 2012;59:293-302. 